\title{
ACUTE ON CHRONIC JEJUNO-GASTRIC INTUSSUSCEPTION FOLLOWING PARTIAL GASTRECTOMY
}

\author{
R. A. Roxburgh, F.R.C.S., F.R.C.S.(Ed.) \\ Surgical Registrar, St. Fames' Hospital, Balham, London, S.W. I2
}

RETROGRADE jejuno-gastric intussusception is an extremely uncommon complication of gastro-jejunal anastomosis and the majority of reports refer to its occurrence after gastro-enterostomy rather than after partial gastrectomy. The following instance occurred in a 73-year-old man who had had a Polya partial gastrectomy 19 years previously.

\section{Case Report}

In 1943 Mr. G. A. S. had an antecolic valved Hofmeister partial gastrectomy performed for a high posterior wall gastric ulcer. The operation stood him in good stead for many years but after 12 years he had an attack of epigastric pain lasting an hour and in the following year he suddenly got another attack after drinking one-and-a-half pints of beer. The pain lasted all night and in the morning he vomited; he thought that the vomit might have contained a little blood. By the time that he reached hospital the pain had begun to ease. On examination there was guarding and rebound tenderness in the epigastrium and bowel sounds were scanty. A plain X-ray of the abdomen failed to reveal any gas under the diaphragm and his symptoms were attributed to peritonism associated with the exacerbation of his chronic bronchitis. He was treated with penicillin and after four days his symptoms had disappeared. Gastroscopy subsequently showed no abnormality.

Nineteen years after his gastrectomy (1962) he was again struck down with a severe epigastric pain that came on suddenly whilst he was going for a walk after breakfast. He was able to walk home but the pain, which was unvarying and cramplike, got steadily worse and in the afternoon he was obliged to send for his doctor who thought that he was suffering from a perforated stomal ulcer and arranged for his admission to hospital. When seen at 6.15 p.m. he was pale and evidently in great pain, but his general condition was good (temperature normal, pulse $110 / \mathrm{min}$., blood pressure $190 / 70 \mathrm{~mm} \mathrm{Hg}$.) and he had not vomited. His abdomen was tender and rigid in the epigastrium but the lower abdomen was relatively soft. No mass was palpable. Bowel sounds were scanty. Although a perforated stomal ulcer seemed the most probable diagnosis his general appearance did not seem tc be quite right for a patient with a perforated viscus of some ten hours duration, the physical signs were confined to the upper abdomen, and there was no free gas under the diaphragm on radiological examination. Furthermore, there had been no recent history such as to suggest that he might have a stomal ulcer. As his serum amylase was only 32 units the diagnosis of perforated stomal ulcer was nevertheless allowed to stand and laparotomy was undertaken that evening.

Operation. After opening the abdomen the gastric remnant was picked up so as to be able to feel the stoma and much to our surprise about a foot $(30.5 \mathrm{~cm}$.) of afferent jejunum reeled out of the stomach without any assistance beyond the mere lifting up of the latter. The intussuscepted jejunum was perfectly healthy in ap- pearance. There was no stomal ulcer nor any evidence $\stackrel{\mathbb{D}}{\Omega}$ of acute pancreatitis. The afferent loop was about a foot long; it was not involved in the intussusception. ${ }^{\infty}$ The efferent loop could readily be intussuscepted again, $\vec{O}$ indeed it almost gave the impression of preferring to liein the intussuscepted position. After a little manipu- $\vec{\omega}$ lating it was found that it could no longer be intussuscepted if it was held to the greater curvature of the gastric remnant. In an attempt to prevent recurrence 3 the loop was therefore stitched in this position over adistance of about an inch $(2.5 \mathrm{~cm}$.) and after making sure $\vec{\circ}$ that this did not result in any awkward angulation the abdomen was closed. The patient made an uneventful recovery and has remained well since.

\section{Discussion}

The first case of jejuno-gastric intussusception to follow partial gastrectomy was reported in 1944 (McNamara, 1944) although by that time 50 caseso had been reported following gastro-enterostomy (Poliquin, 1944). A review of the literature singe $\overrightarrow{0}$ 1952 reveals that some 30 cases following partfil gastrectomy have been reported during the past ten years alone so that retrograde intussusceptioni응 following partial gastrectomy, although still rare, 푼 no longer a curiosity. Since it is hardly ever diag-ō nosed correctly preoperatively (unless either the surgeon or, rarely, the patient, has met with it $\mathbb{Q}$ before) it may be as well to draw attention to the condition from time to time for if the diagnosis of the acute variety is missed the penalty is death.

The acute variety should be borne in mind when a patient who has previously had a gastric operation presents with severe abdominal pain and vomiting.을 The vomitus is often, but not invariably, bloody and 3 . this has on several occasions led the attendant into thinking that he was dealing with a common and relatively benign medical emergency when in reality he has had one of the rarest and most dangerous of surgical emergenices on his hands. 0 As Moroney (1948) says: 'The essential lesion, which is a high and dangerous small bowel ob- $\frac{7}{0}$ struction, (may be) masked by the profuse hæmatemesis'. Close questioning may however reveal that when the vomiting began it was not bloodstained and this together with the fact that half the 0 cases have a tender mass in the epigastrium will help to differentiate the condition from an ordinaryo hæmatemesis. The presence of pain will also puto the physician on guard but there have been cases in which pain was minimal or absent, although this is unusual.

Patients with the chroxic variety complain that from time to time following their gastric operation they have had attacks of epigastric discomfort, or $\frac{\rho}{\bar{\Phi}}$ 
pain, and vomiting. This type is much less dramatic in its presentation and resolves spontaneously. Unless a radiograph taken during an attack shows jejunum lying within the stomach the diagnosis can never confidently be made. This was however achieved in the cases reported by Chamberlin (1940) and Sibley (1944) and in both instances the intussusception had reduced itself by the time laparotomy was undertaken. In the present case the two previous attacks and the readiness with which the intussusception could be reduced and reproduced at operation lead one to suppose that it was an 'acute on chronic' intussusception and the absence of vomiting was due to the fact that the condition had not long been present.
Urgent operation is imperative as soon as the patient has been made fit to withstand it. Resection of a gangrenous intussusceptum may be required but apart from this all that is necessary is reduction of the intussusception. Recurrence is a matter of the very greatest rarity and in two reported cases (Burdman, 1954; Douglas, 1954) recurrence had taken place despite measures that were taken on the first occasion to prevent it. The greatest service that the surgeon can render to his patient is to recognise the condition at the outset and not to prolong the operation by trying to prevent what will probably never happen again.

My thanks are due to Mr. Norman Tanner for permission to report this case.

\section{REFERENCES}

Burdman, M. (1954): Report of a Thrice-recurring Retrograde Intussusception of the Efferent Loop of Jejunum Through a Gastroenterostomy Stoma with a Theory as to the Ætiology, Postgrad. med. Y., 30, 200.

Chamberlin, G. W. (1940): Chronic Recurrent Jejunogastric Intussusception Through a Gastroenterostomy Stoma, Amer. Y. Surg., 49, 510.

Douglas, W. K. (1954): Recurrent Retrograde Gastrojejunal Intussusception, Postgrad. med. Ұ., 30, 204.

McNamara, W. L. (1944): Retrograde Jejunogastric Intussusception Through a Subtotal Gastrectomy Stoma, Ann. Surg., 120, 207.

MoRonEY, J. (1948): Some Interesting Gastrojejunal Lesions, Brit. F. Surg., 35, 374.

Poliquin, P. A. (1944): L'Invagination Jejunogastrique, Un. méd. Can., 73, I8.

Sibley, W. L. (1934): Chronic Intermittent Intussusception Through the Stoma of a Previous Gastroenterostomy, Proc. Mayo Clin., 9, 364 .

\section{A CASE OF APLASTIC ANAEMIA TREATED BY ISOLOGOUS BONE MARROW INFUSION}

\author{
D. E. PegG, M.D. \\ Lecturer in Hamatology, Westminster Hospital, \\ London, S.W.I
}

\author{
W. J. D. Fleming, M.B., B.Chir. \\ Senior Lecturer in Hamatology, Royal Free Hospital, \\ London, W.C.I
}

Nigel Compston, M.A., M.D., F.R.C.P.

Physician, Royal Free Hospital, London, W.C.I

JACOBSON and his colleagues have shown in a series of most elegant experiments that shielding part of the haemopoietic tissue during irradiation, or the post-irradiation implantation of healthy isologous haemopoietic tissue will restore the bone marrow cellularity of irradiated animals (Jacobson and Simmons, 1948; Jacobson, Marks, Gaston, Robson and Zirkle, I949; Jacobson, Marks, Robson, Gaston and Zirkle, 1949; and Jacobson, Simmons, Marks, Robson, Bethard and Gaston, 1950). These observations were extended by Lorenz and his co-workers, when it was demonstrated that the intravenous infusion of viable isologous marrow cells prevented the death of lethally irradiated mice and guinea pigs (Lorenz, Uphoff, Reid and Shelton, I95I). Attempts to use homologous instead of isologous marrow soon revealed difficulties and dangers inherent in the transfer of cells between genetically distinct animals; the homologous marrow proved to be less effective (Lorenz, Congdon and Uphoff, I952) and it frequently produced secondary disease (Barnes and Loutit, 1954; Mathé, Bernard, deVries, Schwarzenberg, Larrieu, Lalanne, Dutreix, Amiel and Surmont, 1960). It is not surprising, therefore, that when marrow infusion techniques come to be applied in clinical medicine, great interest should be given to those circumstances where the experimental isologous situation can be duplicated in man, that is, where an identical twin can be used as the marrow donor. In addition, it was a logical extension of the radiation protection work to attempt to treat the bone marrow aplasia of disease states by isologous marrow 